Imagen fotográfica del tiempo. La obra de Plossu y de IAsparra

Vanesa Magnetto

Metal (N. $\left.{ }^{\circ} 4\right)$, e003, julio 2018. ISSN 2451-6643

https://doi.org/10.24215/24516643e003

http://papelcosido.fba.unlp.edu.ar/ojs/index.php/metal/

Facultad de Bellas Artes. Universidad Nacional de La Plata

\title{
IMAGEN FOTOGRÁFICA DEL TIEMPO LA OBRA DE PLOSSU Y DE IASPARRA
}

\author{
PICTURE OF TIME \\ The Work of Plossu and IAsparra \\ Vanesa Magnetto \\ vanesamagnetto@gmail.com \\ Departamento de Artes Dramáticas y Área de Artes Multimediales. \\ Universidad Nacional de las Artes / CONICET. Argentina
}

\begin{abstract}
This paper develops around the representation and construction of time in the photographic image. We propose two axes of analysis (technical and spatial) to visit the collection of pictures, composed by El Jardín de Bernard, by Bernard Plossu, and Paisajes, by Ignacio lasparra. The problem proposed by this paper should be seen as the potential of Time in these pictures for resisting the hegemonic photographic language, governed by a present, instantaneous image, in close dialogue with contemporary global time and the capitalist system.
\end{abstract}

Keywords

Photography; time; space; Fresson process

\section{Resumen}

El presente artículo gira en torno a la representación y a la construcción del tiempo en la imagen fotográfica. A partir del estudio de dos ejes (técnico y espacial) se analizará el corpus de fotos elegidas, compuesto por El Jardín de Bernard, del fotógrafo Bernard Plossu, y la serie Poisojes, de Ignacio lasparra. El objetivo es identificar la potencialidad que estas imágenes tienen al articular un relato temporal que difiere del lenguaje hegemónico fotográfico y que se resiste a él; un lenguaje regido por una imagen presente, instantánea, en estrecho diálogo con el tiempo global contemporáneo del sistema capitalista.

\section{Palabras clave}

Fotografía; tiempo; espacio; proceso Fresson 
«El artista comprime el tiempo y simultáneamente lo dilata en la inmovilidad de la fotografía.» Hiroshi Sugimoto (1998)

En este trabajo reflexionaremos sobre la representación del tiempo (con respecto al espacio) en el dispositivo fotográfico. Nos interesa indagar en la construcción temporal fotográfica, atendiendo tanto al uso técnico del dispositivo como al aspecto estético que la imagen manifiesta. Si pensamos en la etimología de la palabra fotografía, su definición remite al acto de escribir con luz. Este gesto de escritura implica cierto tiempo de producción que responde al tiempo de exposición de la toma, es decir, al lapso temporal técnico del dispositivo que produce la condición de posibilidad de la imagen. Ésta es completada con su objeto, siguiendo a Charles Sanders Peirce (1984), objeto en tanto concepto, que resulta en motivo de la imagen.

En función de dos aspectos, técnico y espacial, y ubicándonos en el marco de un enfoque semiótico-estético que propone leer una imagen fotográfica como un texto (entendido como un tejido), planteamos dos ejes temporales de análisis: el tiempo de exposición fotográfico (tiempo técnico necesario para la realización de la toma) y el tiempo de enunciación fotográfica (imposible de pensar por fuera del espacio que motiva la fotografía). Estos ejes articularán la lectura y el análisis de las dos series fotográficas que se trabajarán: El Jardín de Bernard (1964-2009), del fotógrafo Bernard Plossu, y Poisojes (1999-2002), de Ignacio lasparra.

Estudiaremos, entonces, dos recursos fotográficos que se desmarcan de la gramática fotográfica hegemónica y que problematizan el carácter realista de la fotografía. Para ello, trabajaremos con el proceso fotográfico Fresson - puesto 
en práctica por Bernard Plossu en su serie- y con el recurso de los largos tiempos de exposición utilizado en la serie Paisojes, de Ignacio lasparra. La selección del corpus responde a que son fotografías contemporáneas del ámbito local e internacional, que reflexionan a partir de estos recursos sobre la dimensión temporal y sobre el propio dispositivo fotográfico para configurar, a través del uso de estos procedimientos, una postura contrahegemónica a las tendencias globales propias del sistema capitalista.

\section{El tiempo como proceso}

La manipulación temporal es imprescindible para la producción de cualquier tipo de discurso artístico. Toda actividad (artística, científica o cotidiana) necesita de un tiempo lineal para ser ejecutada. Nos interesa, entonces, subrayar la particularidad del tiempo fotográfico respecto del que poseen otras artes, ya que es en esta singularidad donde encontramos una oscilación que recorrerá todo el trabajo y que se referirá, por un lado, al tiempo técnico y, por otro, a la representación conceptual del tiempo.

La noción de tiempo se actualiza en una larga discusión. Es exhaustiva la lista de autores que, a partir de diferentes disciplinas y miradas, han debatido y pensado en el tiempo como un concepto. En este sentido, nos interesa tomar como referencia algunas nociones planteadas por Andrei Tarkovksi (2002):

El tiempo es imprescindible para el hombre, para constituirse como tal, para realizarse como individuo. Pero que quede claro que yo no estoy pensando en el tiempo lineal, sin el que nada puede hacerse, ningún paso se puede dar. Porque ya el paso es un resultado. Y a mí me interesa el fondo, del que se alimenta el hombre éticamente. Tampoco la historia es el tiempo ni siquiera la evolución lo es. Los dos términos hacen referencia a una sucesión. Y el tiempo es una situación, el elemento que da vida al alma humana, en el que el alma está en el hogar como la salamandra en el fuego (p. 77).

El autor plantea la noción de tiempo a partir de sus cualidades interiores, morales e inmanentes. Se corre de la concepción clásica del tiempo como sucesión y lo entiende como una situación, una idea. El tiempo como un hecho que vive en la obra. Nos interesa perseguir y desmenuzar esta reflexión en las dos series fotográficas a analizar, ya que ambas, de diferentes maneras, construyen una imagen en la que habita el tiempo.

Con respecto al dispositivo fotográfico, partimos del enfoque de Giorgio Agamben (2014), quien siguiendo a Michael Foucault, define el concepto de dispositivo como una red, una formación que media, inscripta en un juego 
de poder y de saber en el que prevalece una función estratégica dominante. Según esta definición, leemos el uso y la difusión del dispositivo fotográfico con relación a los tiempos capitalistas y globales actuales. La fotografía es un invento moderno y, como tal, se "perfeccionó» como consecuencia de ir detrás de la idea de una imagen fotográfica que reprodujese el objeto a fotografiar de manera mecánica y realista, buscando una imagen espejo en relación a su referente. Para alcanzar esta meta, dejó de lado los tiempos largos de exposición y otras técnicas incipientes porque distorsionaban y alteraban los motivos fotografiados. También se alejó de las referencias pictóricas que daban cuenta de una marca autoral y se acercó a una imagen fotográfica pulcra, sin rastros humanos; una imagen mágica que reflejaba la realidad capturada y que respondía a las expectativas de transparencia del nuevo dispositivo. En este sentido, para destacar y para adherir a una lectura crítica sobre la imagen espejo, seguimos el planteo de Susan Sontag (1980) quien sostiene que «el surrealismo está en la médula misma de la empresa fotográfica: en la creación de un duplicado del mundo, de una realidad de segundo grado, más estrecha pero más dramática que la percibida por la visión natural» (p. 62). Al extender el carácter surreal a todo el lenguaje fotográfico, Sontag problematiza la reputación de la fotografía como la más realista y accesible de las artes miméticas. De este modo, pone en crisis la noción de tiempo y lo caracteriza como conmovedor, irracional, inasimilable y misterioso: «Lo que vuelve surreal a una fotografía es su irrefutable patetismo como mensaje de un tiempo ido» (Sontag, 1980, p. 64).

\section{La actualización del proceso Fresson}

Estamos frente a la obra de Bernard Plossu, fotógrafo vietnamita que ha vivido gran parte de su vida entre América y África. Creemos que la cantidad de viajes y de vivencias en los diferentes lugares por los que habitó con el papel de documentalista, despertaron en él la curiosidad por el espacio manchado con el tiempo. La serie fotográfica El jordín de Bernard fue realizada en el transcurso de casi cincuenta años. Esta obra, a diferencia del resto de su producción, no responde a un proyecto documental-artístico en torno a una temática puntual, sino a una colección de espacios que acompañaron al fotógrafo; espacios en donde lo temporal aparece como un fantasma nostálgico. El recurso que amalgama las imágenes es el proceso Fresson. Su utilización da como resultado visual una especie de anacronismo impreciso que alcanza a la imagen y su espacio.

Comencemos por definir este anacronismo con relación al aspecto técnico del proceso fotográfico. En 1899, a poco más de cincuenta años del descubrimiento de la fotografía, se creó el proceso Fresson, basado en una síntesis química que permitía realizar ampliaciones fotográficas sobre papel carbón. La utilización del 
carbón y su relación con los pigmentos y los haluros de plata (propios de todo proceso fotográfico analógico) se traducía en una imagen en la que la textura cobraba protagonismo. Recordemos que a fines del siglo XIX el estilo que había dominado el mundo de la pintura occidental era el impresionismo. Éste influyó en una corriente fotográfica denominada «pictorialista». Si bien los pictorialistas, a diferencia de los fotógrafos academicistas, se alejaban de las artes plásticas porque intentaban instaurar la independencia del arte fotográfico, sus imágenes remitían (en cuanto a la trama, la textura y la composición) al discurso impresionista.

Ahora bien, si pensamos en Bernard y en su serie, podemos decir que el fotógrafo retoma esta técnica en desuso a medidos de la década del sesenta y genera un laberinto de tiempo a través de las imágenes. La decisión de Plossu de reutilizar una técnica que había sido superada por la deficiencia de su imprecisión -ya que generaba una imagen con mucha textura que le quitaba «a las imágenes todo signo de presente» (Facio, 2003, p. 15)-, da cuenta de la intención de construir una imagen que recupera cierto diálogo con el discurso plástico y que refleja las huellas indiciales de su hacer. Su instancia de producción se evidencia en las marcas propias de las placas de carbón que se alejan de la imagen realista fotográfica moderna. Es la materialidad del soporte fotográfico la que condensa y la que da cuenta del proceso utilizado.

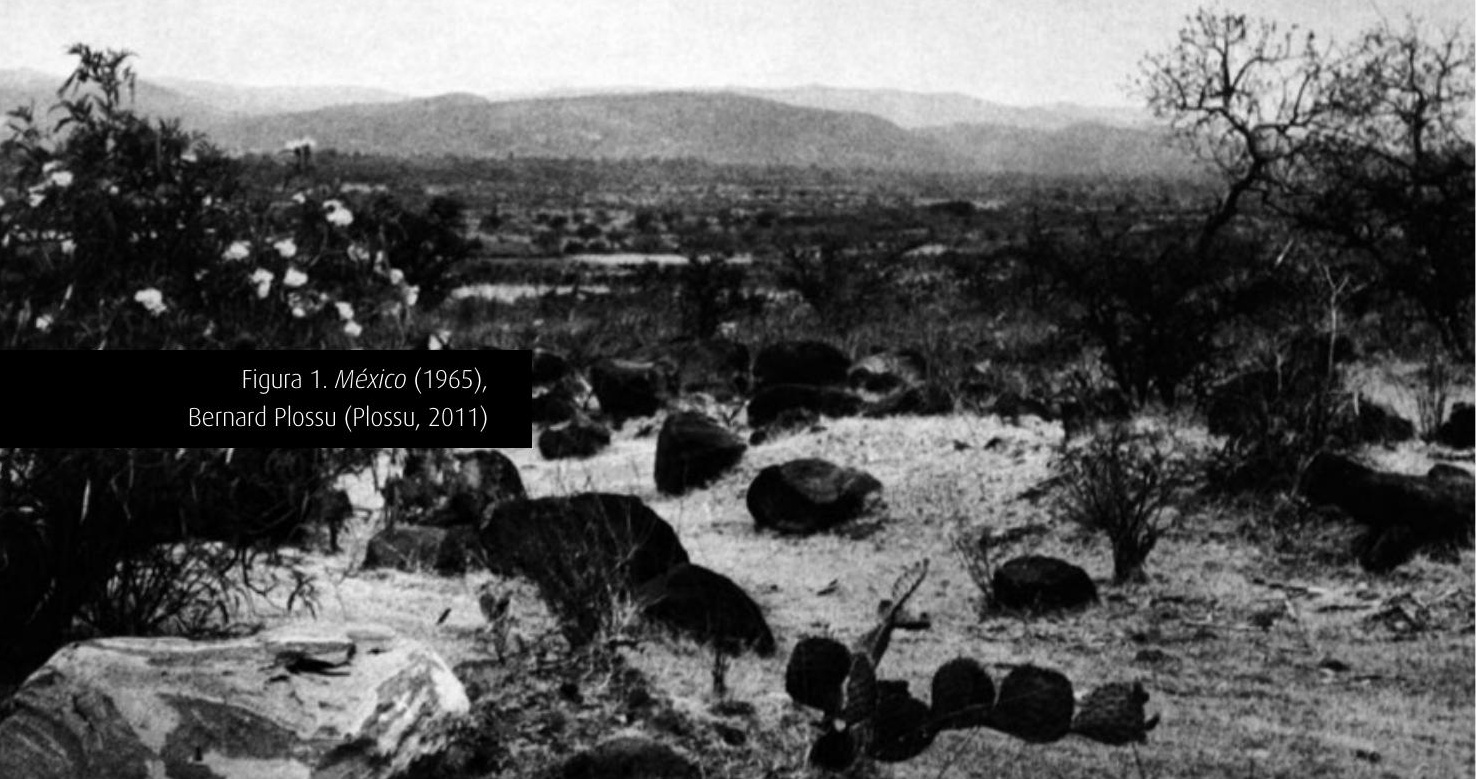




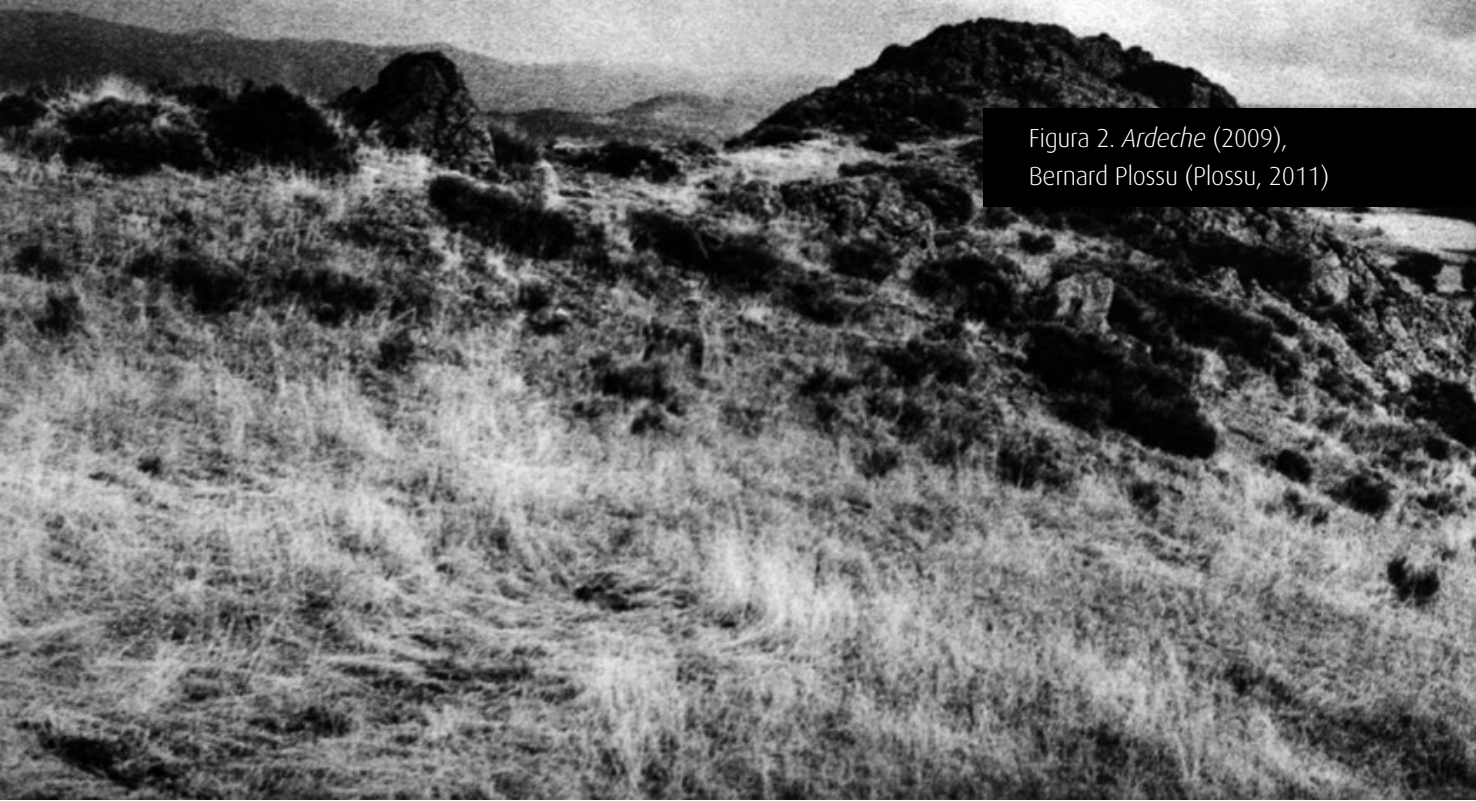

Para puntualizar sobre la cuestión temporal, trabajaremos con los dos ejes mencionados al principio de este texto: el plano técnico y el plano espacial (enunciación). Partimos de la hipótesis de que las imágenes de esta serie cobran una forma atemporal, construida tanto por el aspecto técnico que la genera (el proceso Fresson) como por los motivos y los espacios fotografiados. La técnica fotográfica utilizada remite, en primera instancia, al discurso pictórico. Esta relación se advierte por la textura de la foto, es decir, el grano presente en la imagen resulta en una imagen borrosa. Este efecto flou nos acerca a la pintura impresionista, a una imprecisión sobre lo visto.

Sin embargo, encontramos una diferencia radical en cuanto al lenguaje pictórico y el lenguaje fotográfico. Para entender esta diferencia acudimos a Philippe Dubois (1996), quien afirma que «allí donde el fotógrafo corta, el pintor compone, [...] es el corte operado por la fotografía el que genera un fragmento privado de un acontecer continuo» (p. 154). Este corte es producido por el tiempo necesario para construir la imagen, es decir, el tiempo de exposición fotográfico. En El jardín de Bernard, a diferencia de la serie Paisajes de Ignacio lasparra, el tiempo de exposición no es extremadamente prolongado; si bien resulta más extenso que 1/60 segundo (el tiempo fotográfico estándar de cualquier cámara automática), se acota a una fracción de segundo, acorde a lo que el proceso Fresson requiere. En este breve corte es donde se configura una

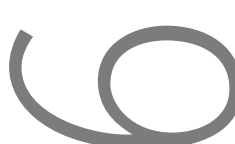


imagen que, corrida de su acontecer continuo, captura el tiempo en ella. No es un extenso tiempo físico dado por la toma de la foto, sino un tiempo espiritual, pensando en Tarkovski (2002), que se aleja de toda datación concreta. Este sabor atemporal es generado, en parte, por la técnica Fresson, que utiliza, en esta serie en particular, fotografías a color corriéndose de un anacronismo en blanco y negro, para apoyarse en la trama de la imagen para producir su aspecto fantasmagórico.

Para complementar el plano estético del eje espacial, recurrimos nuevamente a Dubois (1996):

Todo corte fotográfico instala una articulación entre un espacio representado: el interior de la imagen, el espacio de su contenido, que es el fragmento del espacio referencial transferido en la foto; y un espacio de representación: la imagen como soporte de inscripción, que es construido de manera arbitraria por los bordes del marco. Es esta articulación, entre espacio representado y espacio de representación, lo que define el espacio fotográfico propiamente dicho (p. 192).

El espacio en la fotografía está atado, entonces, a un espacio representado (objeto de la imagen fotográfica) y a un tiempo de corte (tiempo de exposición) que produce el espacio de la representación. En este diálogo enmarcamos el segundo eje de análisis, el tiempo definido en torno al espacio, el registro temporal que percibimos en el enunciado fotográfico.

Gran parte de las fotografías de la serie dan cuenta de paisajes o de espacios al aire libre que (en su mayoría) no presentan marca alguna de cultura. Ejemplificamos con dos imágenes que si bien capturan lugares diferentes, comparten la particularidad de no haber sido moldeadas por la cultura. Se trata de un paisaje desértico de México [Figura 1] y un paisaje en Ardeche, Francia [Figura 2]. Ambas fotografías condensan las coordenadas del tiempo, un tiempo pasado, a través del paisaje originario. A diferencia de los espacios urbanos, que son modificados continuamente por el uso que sus habitantes hacen, ciertos sitios naturales conservan esa imagen de otro tiempo, presentándose como espacios inmemoriales. Al ver este tipo de paisaje, compartimos la mirada originaria, nuestros antepasados la observaron de la misma forma en que la vemos nosotros en el presente, ya que estamos frente a lugares que visualmente no han sido colonizados o modificados por el progreso. El no tiempo vive en él. Y este no tiempo, que podemos definir como un no tiempo histórico, se hace presente en los espacios que Plossu cita a través de sus fotografías. Reforzada por el proceso Fresson, la composición de las imágenes parece 
responder a otra época, alejada de la era digital y de sus manipulaciones. Plossu logra que el espacio de la representación de sus fotografías (delineado por los bordes del marco de la imagen) transforme el tiempo en un hecho, generando una condición atemporal.

\section{Los paisajes de larga duración}

La obra Paisajes fue realizada por el fotógrafo argentino Ignacio lasparra entre 1999 y 2002. Está compuesta por imágenes tomadas en exteriores, espacios rurales y campos, en su mayoría de pueblos de la Provincia de Buenos Aires, Argentina [Figuras 3 y 4]. Conviven en la serie fotografías generadas con largos tiempos de exposición y algunas pocas imágenes producidas con la técnica de la noche americana (utilizada para simular una ambientación nocturna en una escena tomada a la luz del día). Entendemos que es en este cruce, día por noche, noche por día, donde se encuentra el juego propuesto por la obra.

Figura 3. Sin título (2001), Ignacio lasparra. Obra enviada por el autor para ser publicada en este artículo
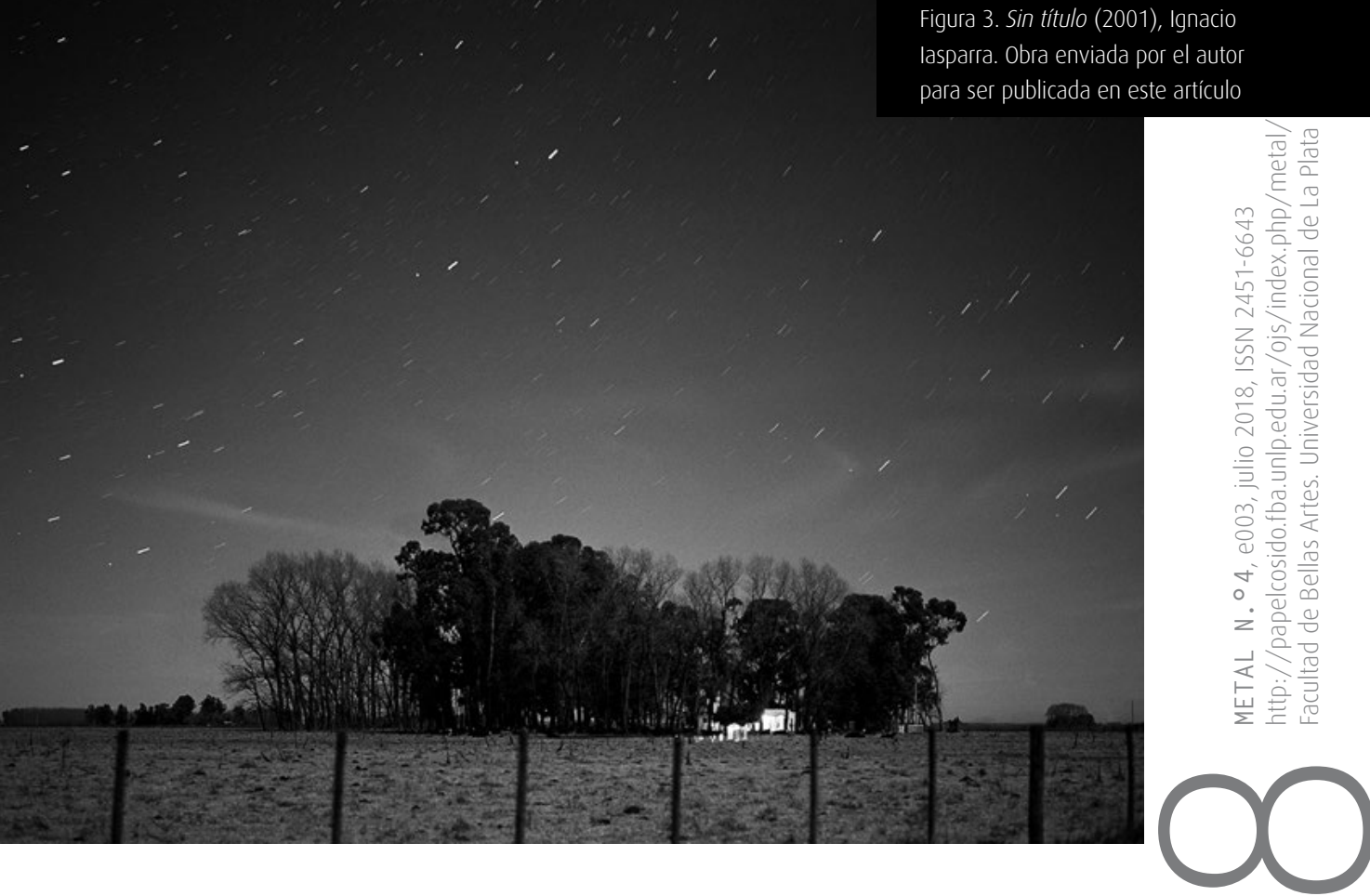
Enlazamos los dos ejes propuestos por este trabajo, técnico y espacial (enunciación), para pensar el carácter poético de estas imágenes. El nivel técnico, basado en este caso en fotografías con largo tiempo de exposición (que oscilan entre tres y veinte minutos de duración), permite generar imágenes que acumulan tiempo y es en esta acumulación en la cual los paisajes (nivel espacial), que motivan la imagen, dan pie y hacen de objeto que se configura en formas y en colores imposibles de percibir por el ojo humano. Las imágenes persiguen un carácter metafórico, muestran más de lo que vemos. La acumulación del tiempo prolongado sobre el soporte fotográfico (película de $35 \mathrm{~mm}$ y $120 \mathrm{~mm}$ ) se traduce en una foto que, si bien permite reconocer los elementos que la habitan (caminos, casas, rutas, luces, ríos, árboles), manifiesta aspectos cromáticos y formales imposibles de captar por la percepción habitual y automática del ojo humano. El tiempo vive en estas imágenes y hace su gracia tiñendo los cielos, trazando la huella del movimiento de las estrellas que evidencian el movimiento del planeta tierra. En estas fotografías persiste el aspecto icónico (se reconocen los objetos y los elementos que aparecen), pero, también, se vislumbra el tiempo a modo de indicio. Si bien no hay manera de percibirlo en forma directa, figurativa, el tiempo cobra forma modificando las apariencias de los objetos y de los espacios fotografiados. 
Cuando se habla del tiempo en la imagen lo que se percibe son huellas, producto de su paso. No se puede observar el tiempo directamente, es invisible, inasible. Estas fotos configuran una simultaneidad temporal esbozada en la imagen. Es en esta simultaneidad, especialmente, en la que la posibilidad de relato fotográfico marca un quiebre respecto al relato cinematográfico, el cual «representa al tiempo a través del movimiento, por necesitar de la sucesión para construir temporalidad» (Deleuze, 2012, p. 187). La fotografía, en cambio, genera un fragmento de tiempo aislado por el gesto fotográfico y este fragmento puede ser un breve recorte temporal o un tiempo más extenso, como en el caso de las fotos de lasparra, que se traduce en una imagen de carácter poético que contiene a un tiempo acumulado.

Por último, queremos hacer una breve observación sobre la técnica de la noche americana, utilizada en menor medida en la serie Paisajes. La simulación de la noche con luz de luna fue un recurso especialmente utilizado por el lenguaje cinematográfico, que cayó en desuso a partir de la aparición de la película fotográfica más sensible (800-1600 ISO), que permitió hacer tomas nocturnas con mayor detalle. La recuperación y el manejo de esta técnica, en la serie, genera un espacio nocturno (enunciación) que se corre de la supuesta referencia mimética fotográfica, al haber sido generado en un espacio diurno. Este recurso se complementa con las fotografías de la serie producidas con largo tiempo de exposición que causaban la impresión de una imagen diurna, pero que respondían a una toma nocturna. Subrayamos, entonces, que lo que vemos en todas las imágenes de la serie Paisajes no se condice con lo percibido por el ojo humano en el momento-espacio de la toma, sino que debemos entender a estas imágenes como signos fotográficos que se escurren de su objeto y que guardan con éste una relación tanto indicial como icónica (Peirce, 1984).

\section{La propuesta final}

Para concluir, recuperamos la propuesta de Susan Sontag (1980), quien entiende a la fotografía como una disciplina surrealista porque sostiene que «la foto no registra, ni da cuenta del tiempo, sino que lo inventa» (p. 59). En este sentido, consideramos fundamental conectar el espíritu de las dos series fotográficas analizadas, ya que de este modo es posible reflexionar sobre nuevos modelos fotográficos que desarticulen el horizonte de expectativa habitual en la utilización del dispositivo fotográfico, permitiendo nuevas configuraciones espacio-temporales. Tanto Plossu como lasparra, a partir de diferentes miradas y procesos técnicos, se corren de la idea de tiempos lentos y de imágenes con textura o con ruido (en cuanto obstáculo) y hacen de ellas un procedimiento estético que invita a pensar en la dimensión temporal desde otra óptica. 


\section{Referencias}

Agamben, G. (2014). ¿Qué es un dispositivo? Buenos Aires, Argentina: Adriana Hidalgo.

Deleuze, G. (2012). Lo Imagen Tiempo. Buenos Aires, Argentina: Paidós.

Dubois, P. (2008). El acto fotográfico y otros ensayos. Buenos Aires, Argentina: La marca editora.

Facio, S. (2003). Encuadre y foco. Buenos Aires, Argentina: La azotea.

Iasparra, I. (1999-2002). Poisojes [Serie fotográfica]. Recuperado de http:// http://www.nachoiasparra.com.ar/index.php?galeria=1

Plossu, B. (2011). El jardín de Bernard. Revista Dulce Equis Negro, 7(12), 5-43. Sontag, S. (1980). Sobre la fotografía. Buenos Aires, Argentina: Sudamericana. Sugimoto, H. (1998). Sugimoto (Fundación la Caixa). Lisboa y Madrid: Fundación La Caixa.

Peirce, CS. (1984). ¿Qué es un signo? En Collected Popers. Cambridge, Estados Unidos: Harvard University Press.

Tarkovski, A. (2002). Esculpir en el tiempo. Reflexiones sobre el arte, lo estético y la poética del cine. Madrid, España: Rialp S.A. 